\title{
Loss of IGF2R indicates a poor prognosis and promotes cell proliferation and tumorigenesis in bladder cancer via AKT signaling pathway
}

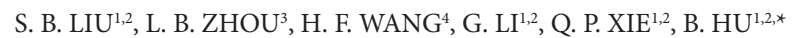 \\ ${ }^{1}$ Department of Urology, Cancer Hospital of China Medical University, Shenyang 110042, Liaoning Province, China; ${ }^{2}$ Department of Urology, \\ Liaoning Cancer Hospital and Institute, Shenyang 110042, Liaoning Province, China; ${ }^{3}$ Department of Urology, Ningbo Medical Center Lihuili \\ Hospital, Ningbo, Zhejiang Province, China; ${ }^{4}$ Department of Urology, The Second Affiliated Hospital of Kunming Medical University, Yunnan \\ Institute of Urology, Kunming, Yunnan Province, China \\ ${ }^{*}$ Correspondence: hubin@cancerhosp-ln-cmu.com
}

Received February 6, 2019 / Accepted July 15, 2019

\begin{abstract}
The insulin growth factor 2 receptor (IGF2R) belongs to insulin growth factor (IGF) pathway and has been proposed as the tumor suppressor in many cancers. However, its role in bladder cancer is unknown. In the current study, we reported that IGF2R expression was decreased in bladder cancer tissues $(\mathrm{p}<0.05)$. Immunohistochemistry (IHC) and Cox regression analysis showed that low IGF2R expression was significantly associated with more advanced histological grade; high clinical stage; lymph node metastasis and poorer overall survival for patients with bladder cancer. Moreover, silencing IGF2R promoted cell proliferation of bladder cancer cells in vitro and in vivo $(\mathrm{p}<0.05)$. Furthermore, knockdown IGF2R resulted in higher phosphorylation level of AKT. The findings of this study indicated that IGF2R played a tumor suppressor role in bladder cancer. Downregulation IGF2R may promote tumor growth by activating AKT signaling pathway. IGF2R could be considered as a promising candidate for novel biomarker and therapeutic target for human bladder cancer.
\end{abstract}

Key words: urinary bladder neoplasms, IGF-2 receptor, AKT signaling pathway, cell proliferation

Bladder cancer is one of the most common cancers in the older population, with metastasis accounting for most of the mortality. The incidence of bladder cancer has steadily risen in recent years. It is estimated that numerous people will be diagnosed with bladder cancer in the next decade. Historically, patients with invasive bladder cancer have favorable prognosis. Whereas $70 \%$ of these tumors will recur within 5 years $[1,2]$. And $50 \%$ of them will evolve to muscle-invasive state. These patients have only $10-15 \%$ five-year survival rate [3]. For these reasons, the identification of key molecules involved in bladder cancer is urgent and highly demanded for improving the clinical outcome.

The insulin-like growth factor (IGF) pathway is known to regulate energy metabolism and growth. Recently, there are considerable evidences for the important role of this transduction network in oncogenesis $[4,5]$. Some members of IGF pathway, like IGF1R and IGFBP5, have been shown to have an ectopic expression in bladder cancer [6-8]. However, the expression of IGF2R in bladder cancer is not fully understood. IGF2R is a multifunctional transmembrane type II receptor $[9,10]$, known for its role in transporting lysosomal enzymes through their mannose 6-phosphate moieties and internalization of extracellular ligands, like IGF2 [11-13]. It is involved in the development of cancer by regulating cell proliferation, migration and apoptosis [14]. Previous studies shown that loss of heterozygosity (LOH) of IGF2R gene might predict a poor clinical outcome in many human cancer (hepatocellular carcinoma, prostate cancer and breast cancer) patients [15-18]. Furthermore, extensive studies reported that loss or mutation of this gene contributed to tumor development and progression [19]. These studies thereby support that IGF2R may act as the tumor suppressor in carcinogenesis. However, whether and how is IGF2R involved in the progression of bladder cancer is unknown.

In the present study, we identified the downregulation of IGF2R in human bladder cancer specimens correlated with poor prognosis. To study the role of IGF2R in bladder cancer, we investigated the effect of IGF2R knockdown in disease progression. We found that IGF2R knockdown significantly promoted cell proliferation and tumorigenesis, and these processes were mediated by enhancing the level of AKT phosphorylation. These findings demonstrate that loss of IGF2R mediated AKT pathway may have a great impact on the human bladder cancer progression. Therefore, targeting 
IGF2R mediated AKT pathway is a useful strategy to inhibit tumor progression.

\section{Patients and methods}

Patients and tissue samples collection. From May 2010 to May 2016, a total of 120 bladder cancer patients (mean age: $50.5 \pm 9.73$ years, ranging from $35-79$ years old; 79 males and 41 females), who had undergone bladder cystectomy and transurethral resection at the Department of Urology of Liaoning Cancer Hospital, were included in this study. The bladder cancer tissue specimens were taken from the non-necrotic tissues at the center of bladder carcinoma (120 cases). All the tissue specimens were fixed with formalin (10\%) after separation. Fresh specimens of bladder cancer and corresponding adjacent tissues from 15 patients with bladder cancer who underwent cystectomy between February 2017 to May 2017 were collected and stored in liquid nitrogen before use. All patients were primary diagnosed and never received any other treatment prior to the surgery. Pathological analysis confirmed that all the patients had transitional cell carcinoma of the bladder, among which, there were 69 cases with non-invasive bladder cancer and 51 cases with invasive bladder cancer. Of all the cases, 33 cases $(27.5 \%)$ were pathologically conformed with lymph node metastasis at the time of diagnosis. Tumor stage was recorded and evaluated according to European Association of Urology (EAU) guideline. The clinicopathological parameters are shown in Table 1. For the experiments involving human subjects, study approval was obtained from the institutional review board of our hospital ethics committee and the study was performed according to the Declaration of Helsinki. Informed consent was obtained from all the patients.

Follow-up methods. Follow-up was performed through outpatient re-examinations and telephone. Patients were followed every 3 months for the first 2 years, with a 6-month interval for the next 3-5 years, and thereafter annually. Follow-up examinations included physical examinations, laboratory studies if clinically indicated. Recurrences were diagnosed by clinical examination, chest radiographs, medical imaging examinations, and/or biopsy was performed where clinically required. Survival time was calculated from the surgery date to the date of death owing to the recurrence or metastasis during the follow-up duration. The last followup was performed until June 30, 2017.

Immunohistochemistry. Tissues were extracted and fixed in $10 \%$ buffered formalin. After embedded in paraffin, dehydrated with graded ethanol, the sections were cut into $5 \mu \mathrm{m}$ slices. The immunohistochemistry was performed using kits (Fujian Maxim Biotechnology Development, Guangdong, China) according to manufacturer's instructions. Briefly, after dewaxed and rehydrated, the tissue slices were blocked with serum, followed by the incubation with primary antibody of anti-IGF2R (1:100, Santa Cruz, USA) at $4{ }^{\circ} \mathrm{C}$ overnight and further incubation with biotinylated secondary antibody (1:100, Santa Cruz) at room temperature for $30 \mathrm{~min}$. Diaminobenzidine (DAB) was used as the final chromogen and hematoxylin was utilized as the counterstain. The OLYMPUS PM20 automatic microscope (Olympus Optical, Tokyo, Japan) and TCFY-2050 pathology system (Yuancheng Inc., Wuhan, China) were used for image acquisitions. The sections were reviewed and scored independently by three observers in a blinded fashion. Positive expression was evaluated with the staining intensity and the percentages of positive cells. Briefly, ten fields were randomly selected for each slice under magnification $400 \times$. The staining intensity scores were divided into three stages depending on the depth of color: 0 point for negative cells, 1 point for yellowish and 2 points for brown. The percentages of positive cells were calculated as the positive cells number in randomly selected 100 cells. Meanwhile, another scoring was performed according to the percentage of positive cells: 0 point for positive cells $<50 \%$, 1 point for $50-75 \%$ positive cells, 2 points for positive cells $\geq 75 \%$. Finally, the low expression case was identified when the sum of two scores was lower than 2 .

Cell culture and transfection. All cells were recovered and cultured in DMEM (Gibco, Carlsbad, CA, USA) containing $1 \%$ fetal bovine serum (Gibco, Carlsbad, CA, USA), $1 \times 10^{5} \mathrm{U} / 1$ of penicillin and $100 \mathrm{mg} / \mathrm{l}$ of streptomycin and incubated in a $37^{\circ} \mathrm{C}$ incubator with $5 \% \mathrm{CO}_{2}$. The cells were seeded onto a 6 -well plate with the density of $5 \times 10^{5}$ cells/well. After $24 \mathrm{~h}$, si-IGF2R was transfected to 5637 cells with Lipofectamine 2000 (Invitrogen, Carlsbad, CA, USA) according to the manufacturer's instructions. For the control group, negative control siRNA was used. Flow cytometry was performed to assess the percentage of positive transfected cells and the cells were continually used for the following experiments when transfection efficiency was higher than $70 \%$. Perifosine (KRX-0401) (Cell Signaling, MA, USA) dissolved in dimethyl sulfoxide (DMSO), was used to treat cells at indicated final concentrations $(30 \mu \mathrm{M})$.

Quantification of mRNA. From RT4, T24, 5637 cell lines and fresh tissue, total RNA was extracted with TRIzol reagent (Invitrogen, CA, USA) following the manufacturer's instructions. The relative expression level of IGF2R was determined by quantitative real-time PCR. We used $\beta$-actin as the internal control.

The primers used were as follows:

IGF2R sense 5'-TCAGACAACGACGGATACAGA-3';

IGF2R anti sense 5'-AAACAAAGCGGACGATAAAA-3';

$\beta$-actin sense: 5'-AGAGCTACGAGCTGCCTGAC-3';

$\beta$-actin anti sense: 5'-AGTACTTGCGCTCAGGAGGA-3'.

Subsequently, PCR products were analyzed using $2 \%$ agarose gel electrophoresis, and then scanned using TanonGIS2010 gel imaging system (Tanon Science \& Technology Co., Shanghai, China).

Western blot. For total protein extraction, cultured cells and xenograft tumor tissues were collected and lysed using lysis buffer on ice for $10 \mathrm{~min}$. After centrifuged at the speed 
A

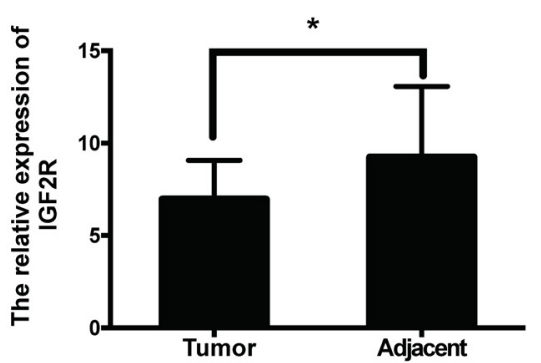

B

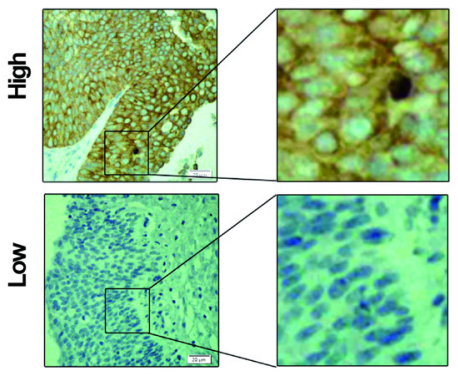

C

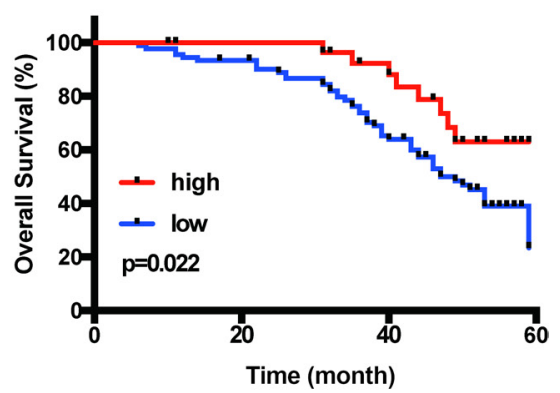

Figure 1. Low IGF2R expression in bladder cancer tissues correlates with poor patient survival. A) IGF2R expression was decreased in bladder cancer tissues compared to normal adjacent tissues $(p<0.05)$. B) Typical images of IGF2R expression in bladder cancer samples from different patients $(1$ sample from 1 patient). Top: high IGF2R expression in bladder cancer sample; Bottom: low IGF2R expression in bladder cancer sample. C) KaplanMeier overall survival curves for all 120 patients with bladder cancer stratified by high and low expression of IGF2R.

of $15000 \times \mathrm{g}$ at $4{ }^{\circ} \mathrm{C}$ for $40 \mathrm{~min}$, the supernatant was collected to determine protein concentration using Protein Quantitation Kit (Sigma Aldrich, St. Louis, MO, USA). About $50 \mu \mathrm{g}$ protein extraction was separated using 10\% SDS-PAGE and transferred onto PVDF membranes. Then the membranes were blocked in PBS with 5\% skim milk for $2 \mathrm{~h}$, followed by the incubation with primary antibodies of anti-IGF2R (1:200, Santa Cruz), anti-AKT, anti-P-AKT (1:350, Santa Cruz) or anti- $\beta$-actin (1:200, Sigma-Aldrich, MO, USA) at room temperature for $2 \mathrm{~h}$ or at $4{ }^{\circ} \mathrm{C}$ overnight. After washing with PBS, the membranes were incubated with the horseradish peroxidase-labeled goat anti-mouse $\operatorname{IgG}(1: 1000$, Santa Cruz, USA). Finally, the immune-reactive bands were visualized using 3,3'-diaminobenzidine (DAB, SigmaAldrich, USA) and detected using chemiluminescence (ECL) detection system (7Sea-Pharm Tech, Shanghai, China). The experiments were replicated for three times.

MTT assay. Cells were seeded in 96-well microplates at the density of $0.3 \times 10^{4}$ cells per well. All groups of cells were incubated in culture medium containing $20 \mu \mathrm{l}$ MTT solution (5 mg/ml, Sigma-Aldrich) for $4 \mathrm{~h}$ at $37^{\circ} \mathrm{C}$ at $12,24,48$ and $72 \mathrm{~h}$ after seeding. The medium was removed, and formazan crystals were measured at 490/570 nm with Gel Documentation and Analysis System set.

Xenograft tumor model. Six-week-old NOD/SCID mice were purchased from Shanghai SIPPR-BK Experimental Animal Co. (Shanghai, China). All experiments were approved by the Institutional Committee on Animal Research and Ethics of China Medical University. Each mouse was assigned to receive subcutaneous inoculation of 5637 cells $\left(5 \times 10^{6}\right)$ on the mammary pads (Negative-RNAi on the left; IGF2R-RNAi on the right). The length (L) and width (W) of tumors were measured with calipers every seven days and the volumes $(\mathrm{V})$ were calculated by a modified ellipsoidal equation $\mathrm{V}=\left(\mathrm{L} \times \mathrm{W}^{2}\right) / 2$. The mice were euthanized on day 28 , and the tumors were excised, photographed and assayed by western blot.
Statistical analysis. All data were analyzed using SPSS version 23.0 (SPSS Inc., Chicago, IL, USA) and GraphPad Prism version 7.0 (GraphPad Software, Inc., La Jolla, CA, USA) [21]. Chi-squared test were performed to value statistically significant between clinical features and IGF2R expression. Then survival curves were plotted by the Kaplan-Meier method and difference was analyzed by the log-rank test. Furthermore, the prognostic value of IGF2R was evaluated using univariate and multivariate Cox regression analyses [22]. All two-side p-value of less than 0.05 were considered statistically significant.

\section{Results}

IGF2R is downregulated in bladder cancer. QPCR experiment was performed to demonstrate whether the expression of IGF2R differs between bladder cancer and normal adjacent tissue. 15 fresh tumor tissues from patients with adjacent tissue were collected. Decreased IGF2R mRNA levels were observed in bladder cancer tissues compared to that in normal adjacent tissues (Figure 1A) $(\mathrm{p}<0.05)$. These data indicate that the expression of IGF2R was lower in bladder cancer tissues than in normal adjacent tissue.

Low IGF2R expression indicates a poor prognosis in bladder cancer. We did IHC in 120 cases of bladder cancer specimens to explore the frequency of IGF2R downregulation. Patients with bladder cancer were divided into high and low expression groups by scores. Results showed that 36 cases $(30 \%)$ were considered as high expressing IGF2R (Figure 1B), detected in the cytoplasm of tumor cells. The remaining 84 cases $(70 \%)$ showed low expression (Table 1 ). Kaplan-Meier survival curves revealed that a low expression level of IGF2R expression was associated with worse overall survival $(\mathrm{p}=0.022)$ (Figure 1C).

Association between IGF2R expression and clinicopathological characteristics of bladder cancer. As shown in Table 1, the IGF2R expression was associated with several 
Table 1. Relationship between IGF2R expression and various clinicopathological characteristics in patients with bladder cancer $(n=120)$.

\begin{tabular}{|c|c|c|c|c|}
\hline \multirow{2}{*}{ Characteristics IGF2R } & \multirow{2}{*}{$\begin{array}{l}\text { Number of } \\
\text { cases (\%) }\end{array}$} & \multicolumn{2}{|c|}{ IGF2R } & \multirow{2}{*}{ p-value } \\
\hline & & High & Low & \\
\hline \multicolumn{5}{|l|}{ Age (y) } \\
\hline$\geq 60$ & $95(79.2)$ & 30 & 65 & 0.462 \\
\hline$<60$ & $25(20.8)$ & 6 & 19 & \\
\hline \multicolumn{5}{|l|}{ Gender } \\
\hline Male & $79(65.8)$ & 24 & 55 & 0.9 \\
\hline Female & $41(34.2)$ & 12 & 29 & \\
\hline \multicolumn{5}{|l|}{ Tumor size $(\mathrm{cm})$} \\
\hline$\leq 2.5$ & $64(53.3)$ & 18 & 46 & 0.632 \\
\hline$>2.5$ & $56(46.7)$ & 18 & 38 & \\
\hline \multicolumn{5}{|l|}{ Tumor number } \\
\hline Signal & $66(55)$ & 22 & 44 & 0.378 \\
\hline Multiple & $54(45)$ & 14 & 40 & \\
\hline \multicolumn{5}{|l|}{ Histology grade } \\
\hline Low & $55(45.8)$ & 25 & 30 & 0.001 \\
\hline High & $65(54.2)$ & 11 & 54 & \\
\hline \multicolumn{5}{|l|}{ Tumor stage } \\
\hline $\mathrm{Ta}+\mathrm{T} 1$ & $69(57.5)$ & 26 & 43 & 0.033 \\
\hline $\mathrm{T} 2-\mathrm{T} 4$ & $51(42.5)$ & 10 & 41 & \\
\hline \multicolumn{5}{|l|}{ Lymph node metastasis } \\
\hline Yes & $33(27.5)$ & 13 & 20 & $<0.001$ \\
\hline No & $87(72.5)$ & 71 & 16 & \\
\hline \multicolumn{5}{|l|}{ Vital status } \\
\hline Alive & $63(52.5)$ & 31 & 32 & $<0.001$ \\
\hline Dead & $57(47.5)$ & 5 & 52 & \\
\hline
\end{tabular}

Table 2. Result of univariate and multivariate analyses of prognostic factors in bladder cancer by Cox's proportional hazard model $(n=120)$.

\begin{tabular}{lccc}
\hline & p-value & $\begin{array}{c}\text { Hazard } \\
\text { Ratio }\end{array}$ & $\begin{array}{c}\text { 95\% Confidence } \\
\text { Interval }\end{array}$ \\
\hline Univariate analysis & & & \\
IGF2R expression (low vs high) & $<0.001$ & 5.353 & 2.134 \\
$\quad$ Tumor size & 0.077 & 0.619 & $0.363-1.054$ \\
$\quad$ Tumor number & 0.506 & 1.196 & $0.706-2.026$ \\
$\quad$ Histology grade & 0.015 & 2.033 & $1.151-3.590$ \\
$\quad$ Tumor stage & 0.001 & 2.363 & $1.398-3.996$ \\
$\quad$ Lymph node metastasis & 0.001 & 4.449 & $1.906-10.386$ \\
Multivariate analysis & & & \\
IGF2R expression (low vs high) & 0.018 & 3.259 & $1.225-8.667$ \\
$\quad$ Histology grade & 0.683 & 1.133 & $0.622-2.063$ \\
$\quad$ Tumor stage & 0.045 & 1.726 & $1.013-2.942$ \\
$\quad$ Lymph node metastasis & 0.023 & 2.775 & $1.148-6.708$ \\
\hline
\end{tabular}

clinicopathological parameters. The patients with low IGF2R expression were more likely to develop higher histology grade $(\mathrm{p}=0.001)$, higher tumor stage $(\mathrm{p}=0.033)$, lymph node metastasis $(\mathrm{p}<0.001)$ and worse vital status $(\mathrm{p}<0.001)$. However, other parameters listed in Table 1 (age, gender, tumor size and tumor number) showed no significant correlation with IGF2R expression ( $\mathrm{p}>0.05$, Table 1$)$.
Cox univariate and multivariate analysis of prognostic factors in bladder cancer. Cox univariate and multivariate analyses were used to evaluate several risk factors associated with prognosis of patients with bladder cancer. Univariate analysis showed that IGF2R expression, histology grade, tumor stage and lymph node metastasis were significantly associated with the risk of death in bladder cancer patients $(\mathrm{p}<0.05$, Table 2$)$. Moreover, multivariate analysis that included all the above significant parameters identified low IGF2R expression, tumor stage and lymph node metastasis as independent prognostic indicator for overall survival $(\mathrm{p}<0.05$, Table 2$)$.

Loss of IGF2R promotes cell proliferation of bladder cancer in vitro. In order to identify the function of IGF2R, the IGF2R mRNA levels and cell growth activities were analyzed in three bladder cancer cell lines. The expression levels of IGF2R were significantly higher in 5637 cells than T24 and RT4 cells (Figure 2A). On the contrary, the cell growth activity of 5637 cells was significantly lower than the other two cell lines (Figure 2B). Based on the above results, 5637 cells were selected for the following assays. IGF2R was knocked down by transfecting specific IGF2R siRNA in 5637 cells. The inhibition efficiency of IGF2R siRNAs (RNAi1, RNAi2 and NC) was measured by QPCR (Figure 2C). We selected the IGF2R RNAil, which had the highest efficiency interference to further study the mechanism and functional consequences of loss of IGF2R expression on the cell growth. The growth was measured by MTT assay after 24,48 and $72 \mathrm{~h}$ transfection. The data indicated that deregulation IGF2R significantly increased the proliferation of 5637 cells (Figure 2D).

Loss of IGF2R promotes the tumorigenesis of bladder cancer cells in vivo. To determine the function of IGF2R in tumorigenesis in vivo, we generated a novel xenograft model in BALB/c nude mice by crossing IGF2R-RNAi1 and NC-siRNA 5673 cell lines. Deregulation of IGF2R in vivo in the IGF2R-RNA1 derived xenograft tumors was confirmed by western blot (Figure 3C). As shown in Figure $3 \mathrm{~A}$, we found an increased in tumor formation in the group of IGF2R-RNAil. Tumor volume and tumor growth curves were significantly enhanced in mice bearing IGF2R knockdown cells (Figure 3B). In summary, knockdown of IGF2R expression promoted tumor growth in vivo.

IGF2R regulates the activity of AKT signaling pathway. To study the molecular mechanism of IGF2R in bladder cancer, the protein levels of IGF2R, AKT, P-AKT were detected in vitro and in vivo. We found that the expression of P-AKT showed a significant increase with the knockdown of IGF2R not only in vitro but also in vivo (Figures $2 \mathrm{E}$, $3 \mathrm{C}$ ). Meanwhile, the expression level of AKT protein was unchanged (Figures 2E, 3C). To further demonstrate the key role of AKT in the proliferation regulated by IGF2R, we conducted the rescue experiments. The kinase activity of AKT was suppressed by an AKT inhibitor (Perofosine) in IGF2R-downregulated 5637 cells. As shown in Figure 2F, 


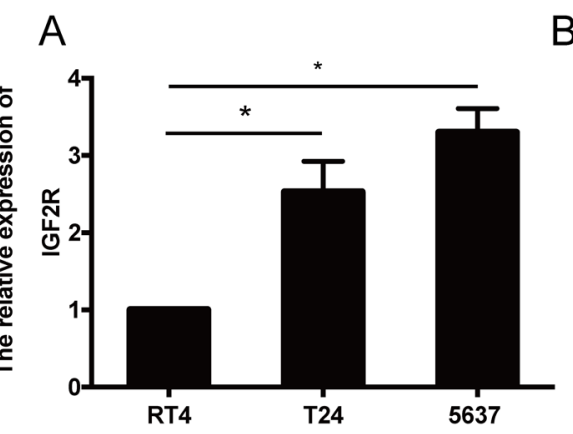

D

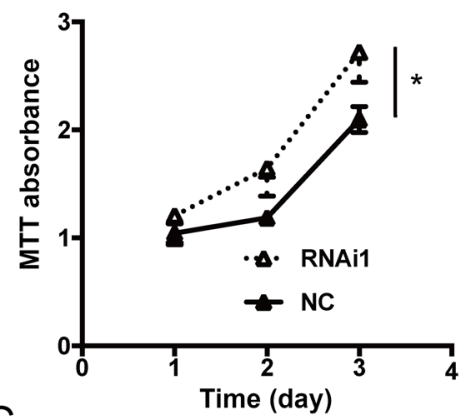

G

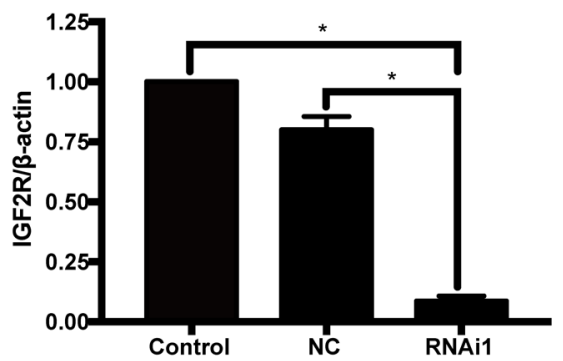

B

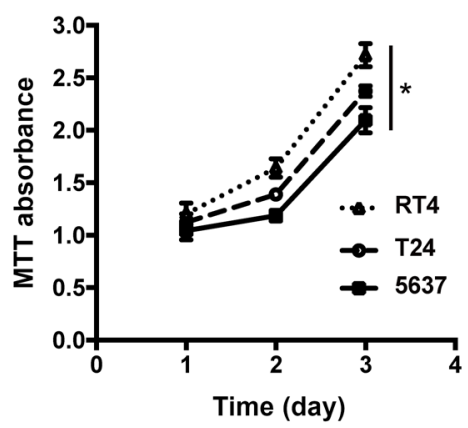

E

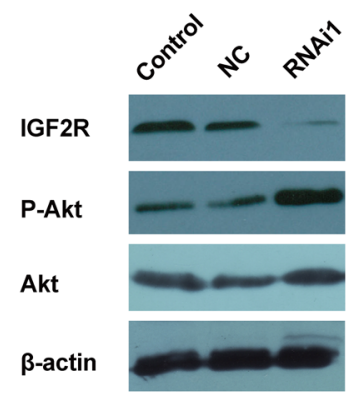

$\mathrm{H}$

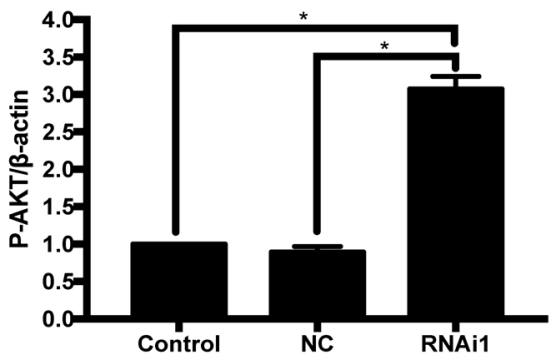

C

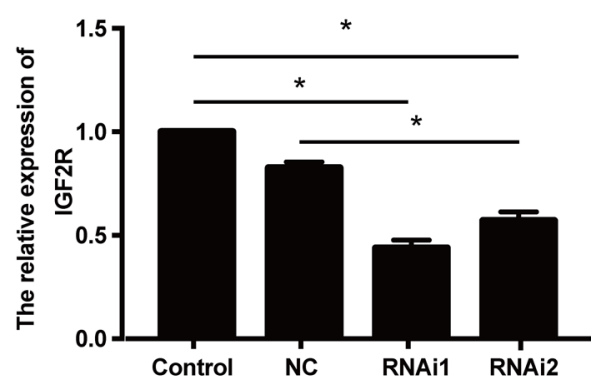

$\mathrm{F}$
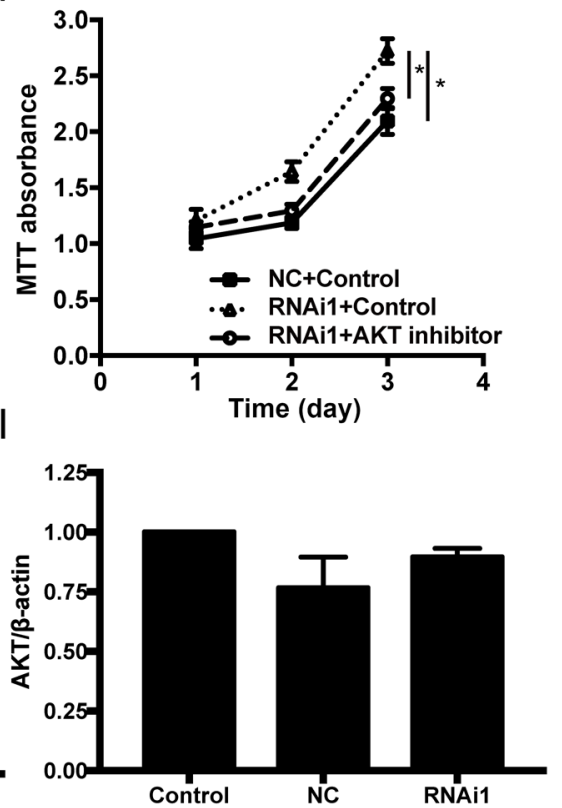

Figure 2. IGF2R modulates proliferation of bladder cancer cells by AKT signaling pathway. A) QPCR analysis of IF2R expression in three bladder cancer cell lines. B) MTT assays reveal the cell growth ability in three different bladder cancer cell lines. C) Knockdown IGF2R by transfecting specific IGF2R siRNA in 5637 cells. D) MTT assays revealed that downregulation of endogenous IGF2R significantly increased the growth rate. E) Western blot analysis of IGF2R, P-AKT, AKT expression in indicated cells. F) MTT assays revealed the role of AKT in the proliferation of IGF2R-RNAi 5637 cell lines. G-I) The expression levels of IGF2R, P-AKT, AKT.

the MTT assay results suggested that the AKT inhibition decreased the cell proliferation. These results indicated that IGF2R silencing might promote the cell proliferation of bladder cancer by activating AKT signaling pathway in vitro and in vivo.

\section{Discussion}

The present study indicated that the expression of IGF2R was downregulated in bladder cancer tissue. Immunohistochemistry analysis demonstrated that low expression of IGF2R was associated with higher histological stage, high tumor stage, lymph node metastasis and reduce survival time of bladder cancer patients. Furthermore, silencing the expression of IGF2R enhanced 5637 cell growth and level of
$\mathrm{P}-\mathrm{AKT}$ in vitro and in vivo. To sum up, our study suggests that IGF2R is a novel biomarker for bladder cancer prognosis and the underlying mechanism may relate to AKT signaling pathway.

The IGF pathway includes three ligands (IGF1, IGF2 and INS), three receptors (IGF1R, IGF2R and INSR), and ten specific IGF-binding proteins (IGF2BP1 to IGF2BP3 and IGFBP1 to IGFBP7) $[4,5]$. These hormones and the signal transduction networks are involved in biological processes such as regulation of cell proliferation, differentiation and migration and suggest an important role in cancer [23-25]. The dysfunctions of IGF pathway were observed in many types of carcinomas. IGF1 and IGF1R were reported to be overexpressed in many cancers, such as lung cancer, hepatocellular carcinoma, breast cancer, pancreatic cancer etc., and 
A

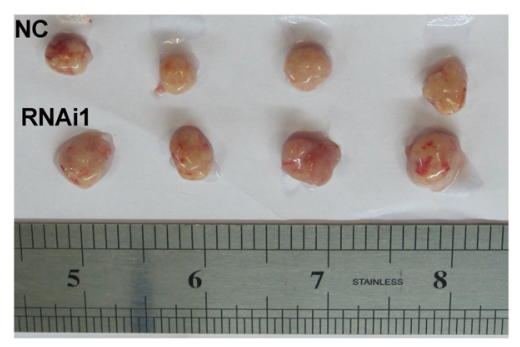

D

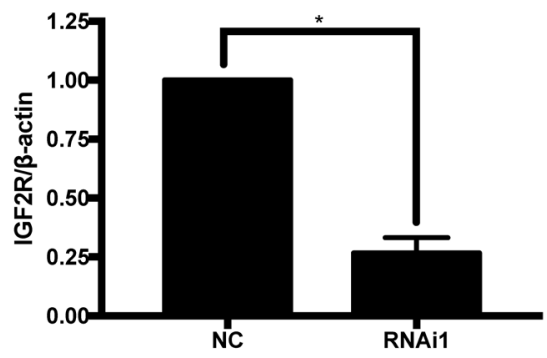

B

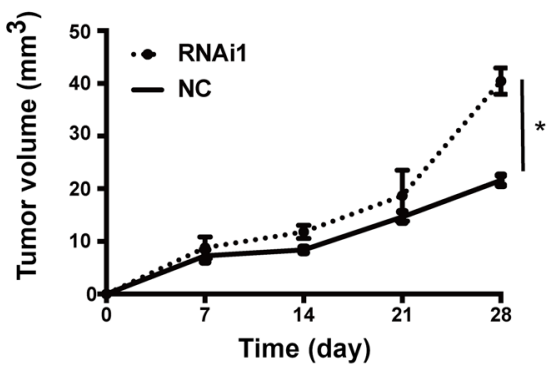

C

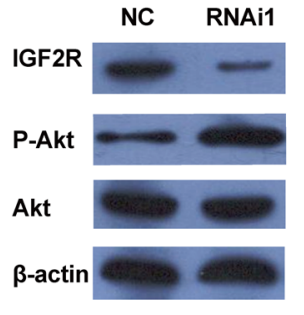

$E$

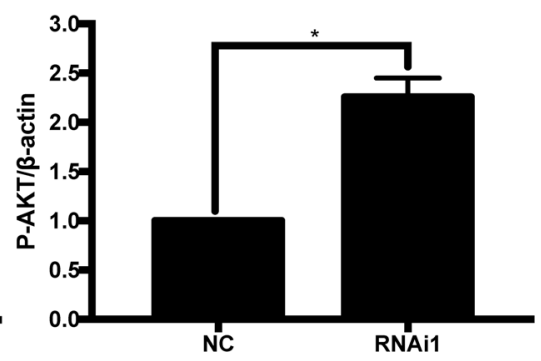

$\mathrm{F}$

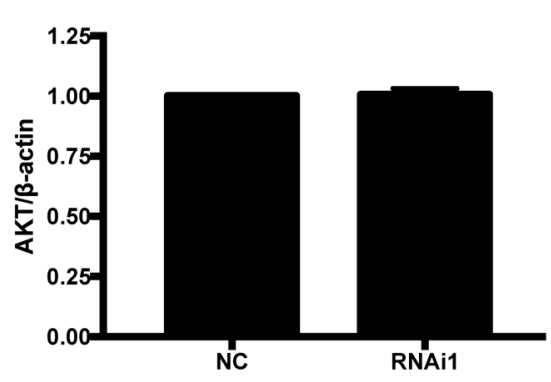

Figure 3. IGF2R regulates the tumorigenesis of bladder cancer. A) Image of excised tumors from four BALB/C nude mice at 28 days after injection with IGF2R-RNAi-transfected cells. B) Tumor volumes were measured every seven days. C) Western blot analysis of IGF2R, P-AKT, AKT expression in tumor tissues. D-F) The expression levels of IGF2R, P-AKT, AKT.

significantly associated with a prognosis [26-29]. Unlikely, IGF2R was considered to serve as a cancer suppressor. Depletion or reduction of IGF2R was observed in hepatocellular carcinoma, breast cancer and prostate cancer [30]. However, the role of IGF pathway in bladder cancer was controversial. Some studies suggested that IGF1R was overexpressed in muscle-invasive bladder cancer tissues and correlated with the prognosis of these patients $[7,30]$. On the other hand, Neuzillet et al. analyzed data from two independent bladder cancer datasets and found that the expression and activation of IGF1R was stronger in non-muscle-invasive than in muscle-invasive bladder cancer [8]. Unfortunately, the study of IGF2R function in bladder cancer is insufficient to be compared with IGF1R. To define the role of IGF2R in bladder cancer, we examined the expression of IGF2R in 15 paired fresh tissue by QPCR assays and found that IGF2R was deregulated in bladder cancer samples. In addition, we did IHC in 120 human bladder cancer tissues and analyzed the correlation between their expression and clinical pathologic factors, and prognosis. As a result, we demonstrated that low expression of IGF2R was significantly associated with the poor clinicopathological features and prognosis of this disease. These findings suggested that loss of IGF2R might act as a potential biomarker to identify bladder cancer with poorer clinical outcomes.

The interaction between IGF2 and IGF2R plays a crucial part in the cellular physiology and pathological process, such as tumor growth, invasion and metastasis. Loss of IGF2R expression has therefore been associated with growth related disease and cancer [31, 32]. Previous study has identified IGF2R as a cell surface target required for tumor cell growth [33]. On the other hand, Probst et al. found that IGF2R inhibited the proliferation of squamous cell carcinoma cells $[34,35]$. Although the growth suppressor role of IGF2R is well demonstrated in many tumors, its impact on bladder cancer remains poorly understood. In the present study, we used bladder cancer cell lines 5637, T24 and RT4 cell lines to study the effects of IGF2R on cell biological. 5637 cells were selected because their IGF2R level was significantly higher than the others. We found increased proliferation in 5637 cells when we decreased the mRNA expression of IGF2R by siRNA. Then we performed a xenograft model by treating 5637 cells with IGF2R siRNA and we found a significantly promoted tumor formation in nude mice compared to negative siRNA. The current study suggested that loss of IGF2R might act as a carcinogenic factor by promoting tumor growth in bladder cancer.

AKT is usually highly activated by its phosphorylation, which promotes cancer cell proliferation in human cancers $[36,37]$. Activating AKT signaling pathways may contribute to the cell proliferation in large number of carcinomas, such as bladder cancer [38]. AKT phosphorylation inhibitors are considered as a promising treatment approach for cancer [39]. However, the function of IGF2R and its modulation of AKT have not been investigated in bladder cancer. Here, we knocked down IGF2R by siRNA, and the protein levels 
of IGF2R, AKT, phosphorylation of AKT (P-AKT) were assayed by western blot. We found the forced overexpression of P-AKT in 5637 cells in vitro and in vivo. Moreover, inhibition of AKT kinase activity neutralized the effects of IGF2R. These results suggest that loss of IGF2R may promote the proliferation and tumorigenicity of bladder cancer via AKT signaling pathway. IGF2R-Akt signaling axis may have the potential to be a novel and valuable target for human bladder cancer.

In conclusion, we show that loss of IGF2R in human bladder cancer tissues is significantly associated with the poor clinical characteristic and prognosis. IGF2R downregulation is important for AKT phosphorylation, thus promoting cancer cell proliferation and tumorigenesis. Our research suggests that IGF2R could be regarded as a potential biomarker and therapeutic target for bladder cancer in the future.

Acknowledgments: This study was supported by Nation cancer center tumor research special subject (grant no. NCC2017A13), Natural Science Foundation of Liaoning (grant no. 20180550399) and The Natural Science Foundation of Ningbo (grant no. 2017A610186). We thank Yi-Chen Chen for excellent technical assistance.

\section{References}

[1] MO M, ZHOU M, WANG L, QI L, ZHOU K et al. CCL21/ CCR7 Enhances the Proliferation, Migration, and Invasion of Human Bladder Cancer T24 Cells. https://doi.org/10.1371/ journal.pone.0119506

[2] ZHANG Y, HUANG Z, ZHU Z, ZHENG X, LIU J et al. Upregulated UHRF1 promotes bladder cancer cell invasion by epigenetic silencing of KiSS1. PLoS ONE 2014; 9: e104252. https://doi.org/10.1371/journal.pone.0104252

[3] LIU W, QI L, LV H, ZU X, CHEN M et al. MiRNA-141 and miRNA-200b are closely related to invasive ability and considered as decision-making biomarkers for the extent of PLND during cystectomy. BMC Cancer 2015; 15: 92. https:// doi.org/10.1186/s12885-015-1110-7

[4] DONG X, JAVLE M, HESS KR, SHROFF R, ABBRUZZESE JL et al. Insulin-Like Growth Factor Axis Gene Polymorphisms and Clinical Outcomes in Pancreatic Cancer. Gastroenterology 2010; 139: 464-473. https://doi.org/10.1053/j. gastro.2010.04.04

[5] SACHDEV D, YEE D. Disrupting insulin-like growth factor signaling as a potential cancer therapy. Mol Cancer Ther 2007; 6: 1-12. https://doi.org/10.1158/1535-7163.MCT-060080

[6] GONZALEZ-ROIBON N, KIM JJ, FARAJ SF, CHAUX A, BEZERRA SM et al. Insulin-like growth factor-1 receptor overexpression is associated with outcome in invasive urothelial carcinoma of urinary bladder: a retrospective study of patients treated using radical cystectomy. Urology 2014; 83: 1444. e1-6. https://doi.org/10.1016/j.urology.2014.01.028
[7] ROCHESTER MA, PATEL N, TURNEY BW, DAVIES DR, ROBERTS IS et al. The type 1 insulin-like growth factor receptor is over-expressed in bladder cancer. BJU Int 2007; 100: 1396-1401. https://doi.org/10.1111/j.1464410X.2007.06931.X

[8] NEUZILLET Y, CHAPEAUBLANC E, KRUCKER C, DE KONING L, LEBRET T et al. IGF1R activation and the in vitro antiproliferative efficacy of IGF1R inhibitor are inversely correlated with IGFBP5 expression in bladder cancer. BMC Cancer 2017; 17: 636. https://doi.org/10.1186/s12885-0173618-5

[9] KORNFELD S. Trafficking of lysosomal enzymes in normal and disease states. J Clin Invest 1986; 77: 1-6. https://doi. org/10.1172/JCI112262

[10] SAHAGIAN GG, NEUFELD EF. Biosynthesis and turnover of the mannose 6-phosphate receptor in cultured Chinese hamster ovary cells. J Biol Chem 1983; 258: 7121-7128.

[11] GODÁR S, HOREJSI V, WEIDLE UH, BINDER BR, HANSMANN C et al. M6P/IGFII-receptor complexes urokinase receptor and plasminogen for activation of transforming growth factor-beta1. Eur J Immunol 1999; 29: 1004-1013. https://doi.org/10.1002/(SICI)15214141(199903)29:03<1004::AID-IMMU1004>3.0.CO;2-Q

[12] KORNFELD S. Structure and function of the mannose 6-phosphate/insulinlike growth factor II receptors. Annu Rev Biochem 1992; 61: 307-330. https://doi.org/10.1146/annurev.bi.61.070192.001515

[13] MORGAN DO, EDMAN JC, STANDRING DN, FRIED VA, SMITH MC et al. Insulin-like growth factor II receptor as a multifunctional binding protein. Nature 1987; 329: 301-307. https://doi.org/10.1038/329301a0

[14] VICIKOVA K, PETROVCIKOVA E, MANKA P, DRACH J, STOCKINGER $\mathrm{H}$ et al. Serum and urinary levels of CD222 in cancer: origin and diagnostic value. Neoplasma 2018; 65 : 762-768. https://doi.org/10.4149/neo_2018_171203N792

[15] JANG HS, KANG KM, CHOI BO, CHAI GY, HONG SC et al. Clinical significance of loss of heterozygosity for M6P/ IGF2R in patients with primary hepatocellular carcinoma. World J Gastroenterol 2008; 14: 1394-1398. https://doi. org/10.3748/wjg.14.1394

[16] HU CK, MCCALL S, MADDEN J, HUANG H, CLOUGH R et al. Loss of heterozygosity of M6P/IGF2R gene is an early event in the development of prostate cancer. Prostate Cancer Prostatic Dis 2006; 9: 62-67. https://doi.org/10.1038/ sj.pcan. 4500842

[17] OKA Y, WATERLAND RA, KILLIAN JK, NOLAN CM, JANG HS et al. M6P/IGF2R tumor suppressor gene mutated in hepatocellular carcinomas in Japan. Hepatology 2002; 35: 1153-1163. https://doi.org/10.1053/jhep.2002.32669

[18] REY JM, THEILLET C, BROUILLET JP, ROCHEFORT H. Stable amino-acid sequence of the mannose-6-phosphate/insulin-like growth-factor-II receptor in ovarian carcinomas with loss of heterozygosity and in breast-cancer cell lines. Int J Cancer 2000; 85: 466-473. https://doi. org/10.1002/(sici) 1097-0215(20000215)85:4<466::aidijc $4>3.0 . \mathrm{co} ; 2-2$ 
[19] CHAPPELL SA, WALSH T, WALKER RA, SHAW JA. Loss of heterozygosity at the mannose 6-phosphate insulin-like growth factor 2 receptor gene correlates with poor differentiation in early breast carcinomas. Br J Cancer 1997; 76: 1558-1561. https://doi.org/10.1038/bjc.1997.596

[20] JIAO F, BAI S-Y, MA Y, YAN Z-H, YUE Z et al. DNA Methylation of Heparanase Promoter Influences Its Expression and Associated with the Progression of Human Breast Cancer. PLoS One 2014; 9: e92190. https://doi.org/10.1371/journal. pone.0092190

[21] SONG L, WANG L, LI Y, XIONG H, WU J et al. Sam68 up-regulation correlates with, and its down-regulation inhibits, proliferation and tumourigenicity of breast cancer cells. J Pathol 2010; 222: 227-237. https://doi.org/10.1002/ path. 2751

[22] TAKATA M, YAMANAKA N, TANAKA T, YAMANAKA J, MAEDA $S$ et al. What patients can survive disease free after complete resection for hepatocellular carcinoma?: A multivariate analysis. Jpn J Clin Oncol 2000; 30: 75-81. https://doi. org/10.1093/jjco/hyd016

[23] DONG X, PARK S, LIN X, COPPS K, YI X et al. Irs1 and Irs2 signaling is essential for hepatic glucose homeostasis and systemic growth. J Clin Invest 2006; 116: 101-114. https:// doi.org/10.1172/JCI25735

[24] WITHERS DJ, BURKS DJ, TOWERY HH, ALTAMURO SL, FLINT CL et al. Irs- 2 coordinates Igf- 1 receptor-mediated $\beta$-cell development and peripheral insulin signalling. Nat Genet 1999; 23: 32-40. https://doi.org/10.1038/12631

[25] POLLAK M. The insulin and insulin-like growth factor receptor family in neoplasia: an update. Nat Rev Cancer 2012; 12: 159-169. https://doi.org/10.1038/nrc3215

[26] NAKAGAWA M, URAMOTO H, OKA S, CHIKAISHI Y, IWANAMI T et al. Clinical Significance of IGF1R Expression in Non-Small-Cell Lung Cancer. Clin Lung Cancer 2012; 13: 136-142. https://doi.org/10.1016/j. cllc.2011.10.006

[27] BROWNE BC, EUSTACE AJ, KENNEDY S, O'BRIEN NA, PEDERSEN $\mathrm{K}$ et al. Evaluation of IGF1R and phosphorylated IGF1R as targets in HER2-positive breast cancer cell lines and tumours. Breast Cancer Res Treat 2012; 136: 717-727. https://doi.org/10.1007/s10549-012-2260-9

[28] TOVAR V, ALSINET C, VILLANUEVA A, HOSHIDA Y, CHIANG DY et al. IGF activation in a molecular subclass of hepatocellular carcinoma and pre-clinical efficacy of IGF-1R blockage. J Hepatol 2010; 52: 550-559. https://doi. org/10.1016/j.jhep.2010.01.015

[29] BADZIO A, WYNES MW, DZIADZIUSZKO R, MERRICK DT, PARDO $M$ et al. Increased Insulin-Like Growth Factor 1 Receptor Protein Expression and Gene Copy Number in Small Cell Lung Cancer. J Thorac Oncol 2010; 5: 1905-1911. https://doi.org/10.1097/JTO.0b013e3181f38f57
[30] MARTIN-KLEINER I, GALL TROSELJ K. Mannose-6phosphate/insulin-like growth factor 2 receptor (M6P/ IGF2R) in carcinogenesis. Cancer Lett 2010; 289: 11-22. https://doi.org/10.1016/j.canlet.2009.06.036

[31] BROWN J, JONES EY, FORBES BE. Interactions of IGFII with the IGF2R/cation-independent mannose-6-phosphate receptor mechanism and biological outcomes. Vitam Horm 2009; 80: 699-719. https://doi.org/10.1016/S00836729(08)00625-0.

[32] KOTSINAS A, EVANGELOU K, SIDERIDOU M, KOTZAMANIS G, CONSTANTINIDES $C$ et al. The 3'-UTR IGF2R-A2/B2 variant is associated with increased tumor growth and advanced stages in non-small cell lung cancer. Cancer Lett 2008; 259: 177-185. https://doi.org/10.1016/j. canlet.2007.10.013

[33] GELMAN MS, YE XK, STULL R, SUHY D, JIN L et al. Identification of cell surface and secreted proteins essential for tumor cell survival using a genetic suppressor element screen. Oncogene 2004; 23: 8158-8170. https://doi.org/10.1038/ sj.onc. 1208054

[34] PROBST OC, KARAYEL E, SCHIDA N, NIMMERFALL E, HEHENBERGER E et al. The mannose 6-phosphate-binding sites of M6P/IGF2R determine its capacity to suppress matrix invasion by squamous cell carcinoma cells. Biochem J 2013; 451: 91-99. https://doi.org/10.1042/BJ20121422

[35] PROBST OC, PUXBAUM V, SVOBODA B, LEKSA V, STOCKINGER $\mathrm{H}$ et al. The mannose 6-phosphate/insulinlike growth factor II receptor restricts the tumourigenicity and invasiveness of squamous cell carcinoma cells. Int J Cancer 2009; 124: 2559-2567. https://doi.org/10.1002/ijc.24236

[36] TAZZARI PL, CAPPELLINI A, GRAFONE T, MANTOVANI I, RICCI F et al. Detection of serine 473 phosphorylated Akt in acute myeloid leukaemia blasts by flow cytometry. Br J Haematol 2004; 126: 675-681. https://doi. org/10.1111/j.1365-2141.2004.05121.X

[37] KUO YC, HUANG KY, YANG CH, YANG YS, LEE WY et al. Regulation of phosphorylation of Thr-308 of Akt, cell proliferation, and survival by the B55alpha regulatory subunit targeting of the protein phosphatase $2 \mathrm{~A}$ holoenzyme to Akt. J Biol Chem 2008; 283: 1882-1892. https://doi.org/10.1074/ jbc.M709585200

[38] WU X, OBATA T, KHAN Q, HIGHSHAW RA, DE VERE WHITE $\mathrm{R}$ et al. The phosphatidylinositol-3 kinase pathway regulates bladder cancer cell invasion. BJU Int 2004; 93: $143-$ 150. https://doi.org/10.1111/j.1464-410x.2004.04574.x

[39] KNOWLING M, BLACKSTEIN M, TOZER R, BRAMWELL V, DANCEY J et al. A phase II study of perifosine (D-21226) in patients with previously untreated metastatic or locally advanced soft tissue sarcoma: A National Cancer Institute of Canada Clinical Trials Group trial. Invest New Drugs 2006; 24: 435-439. https://doi.org/10.1007/s10637-006-6406-7 